\title{
Demanda de irrigação da cultura da uva na Bacia do Rio São Francisco ${ }^{1}$
}

\author{
Wallisson da S. Freitas ${ }^{2}$, Márcio M. Ramos ${ }^{2} \&$ Ângelo M. S. Oliveira ${ }^{3}$
}

\begin{abstract}
RESUMO
Visando subsidiar o planejamento de projetos agrícolas para o dimensionamento de projetos de irrigação e a gestão de recursos hídricos, estimou-se e se espacializou a demanda de irrigação da videira (Vitis vinifera L.), cv. Itália, na bacia do Rio São Francisco. Utilizaram-se séries históricas de dados de 81 estações climáticas distribuídas na bacia. Para cada estação calculou-se os valores, máximos diários e o total anual, da evapotranspiração de referência (ETo), da evapotranspiração da cultura (ETC), da demanda suplementar da cultura e da demanda suplementar de irrigação (este com eficiência de 70\%). Com base nos resultados obtidos, concluiu-se que: (a) a ETc máxima diária variou, em grande parte da bacia, de 4,5 a 5,7 $\mathrm{mm} \mathrm{d}^{-1}$, tendo média anual de $943 \mathrm{~mm}$; (b) em média, a demanda anual suplementar da cultura foi $839,5 \mathrm{~mm}$, equivalente a 103,5 mm inferior à ETc; (c) o fato do sistema funcionar com $70 \%$ de eficiência, em vez de $90 \%$, implica em acréscimo estimado de $18.808 .755 \mathrm{~m}^{3}$ de água por ano, somente nas microrregiões de Juazeiro, BA e Petrolina, PE.
\end{abstract}

Palavras-chave: consumo hídrico, Vitis vinifera L., distribuição espacial

\section{Irrigation demand for grape crop in San Francisco River Basin}

\begin{abstract}
The irrigation water demand of the grapevine (Vitis vinifera L.) Cv. Italy was estimated and spatialized in San Francisco River Basin, in order to subsidize the agricultural project planning and water resource management. Historical data series relative to 81 climatic stations distributed throughout the basin were used. The maximum daily values and the annual total values of the reference evapotranspiration (ETo), crop evapotranspiration (ETC), supplementary demand of the crop and the supplementary irrigation demand (70\% efficiency) were calculated for each station. According to the results, the following conclusions were drawn: (a) in a large area of the basin, the maximum daily ETc varied from 4.5 to $5.7 \mathrm{~mm} \mathrm{~d}^{-1}$, with an annual mean of $943 \mathrm{~mm}$; (b) the supplementary annual demand of the crop averaged $839.5 \mathrm{~mm}$, corresponding to $103.5 \mathrm{~mm}$ less than ETc; and (c) the irrigation system operating with $70 \%$ efficiency instead of $90 \%$ implies an increment of $18,808,755 \mathrm{~m}^{3}$ water per year only in the microregions of Juazeiro, BA and Petrolina, PE.
\end{abstract}

Key words: water requirement, Vitis vinifera L., spatial distribution

1 Projeto financiado pela ONU/OEA/ANA.

2 DEA/UFV. Av. PH Rolfs, s/n, CEP 36570-000, Viçosa, MG. Fone: (31) 3892-5089. E-mail: wallfreitas@yahoo.com.br; Fone: (31) 3899-1914. E-mail: mmramos@ufv.br

${ }^{3}$ DEF/UFV. Fone: (31) 3899-2477. E-mail: angelomarcos@vicosa.ufv.br 


\section{INTRODUÇÃO}

A área cultivada com uva no Brasil, em 2002, foi 65.381 ha, sendo o Rio Grande do Sul o principal produtor, com 36.668 ha, seguido dos estados de São Paulo e Paraná. Nos estados de Pernambuco, Bahia e Minas Gerais, situados em regiões de clima tropical, cultivavam-se 3.365, 2.732 e 950 ha, respectivamente (IBGE, 2002).

O Vale do São Francisco é a principal região vitícola tropical do Brasil, destacando-se os pólos produtores da mesorregião Norte de Minas Gerais (que inclui as microrregiões de Januária, Janaúba e Pirapora) e as microrregiões de Juazeiro, BA, e Petrolina, PE, com áreas de 558, 2.597 e 3.094 ha, respectivamente (IBGE, 2002). A maior parte da produção dessas regiões é destinada ao mercado interno, e as exportações vêm crescendo graças à organização dos produtores (Protas, 2004).

Nesta região a ocorrência de baixas precipitações e alta demanda evaporativa impõem o fornecimento de água através da irrigação. Tanto a deficiência como o excesso hídrico afeta, de maneira marcante, o comportamento dos estádios fenológicos da cultura da videira, comprometendo a qualidade e produtividade dos frutos. A deficiência, quando ocorre durante o período inicial de crescimento das bagas, proporciona redução no tamanho dos frutos; quando acontece durante a maturação, atrasa o amadurecimento, afetando a coloração e favorecendo a queima dos frutos, pela radiação solar. Na fase final de maturação o consumo hídrico da videira diminui. O excesso hídrico, combinado com temperaturas elevadas, torna a cultura muito susceptível a doenças. Para uma boa produtividade, é recomendável que o desenvolvimento vegetativo da planta ocorra em condições de escassez de precipitação pluviométrica e que as necessidades hídricas sejam satisfeitas através da irrigação, de acordo com o requerimento de água da cultura, sendo os métodos de gotejamento e microaspersão os mais utilizados (Teixeira \& Azevedo, 1996).

O dimensionamento hidráulico de projetos de irrigação tem, muitas vezes, como referência, os valores de evapotranspiração médios mensais, que podem variar temporalmente até 50\% e, portanto, não representar valores extremos de períodos menores, em especial os diários (Dantas Neto, 2002). Além disso, segundo Carvalho (1998), a maioria dos projetos envolvendo recursos hídricos, em todo o mundo, não tem alcançado os níveis desejados de produtividade devido, basicamente, às dificuldades operacionais encontradas no campo, não levadas em consideração durante o planejamento.

O conhecimento das demandas de irrigação anual e máxima diária de determinada cultura de uma região possibilita o dimensionamento da rede hidráulica de projetos de irrigação, como canais, tubulações, reservatórios e estações de bombeamento, além da estimativa do volume total de água retirado para suprir suas necessidades hídricas. Tais informações são fundamentais no gerenciamento de recursos hídricos e no planejamento de projetos hidroagrícolas.

Em geral as necessidades hídricas anuais da cultura da uva variam entre 500 e $1.200 \mathrm{~mm}$, dependendo do clima, da duração do ciclo fenológico, do cultivar, da estrutura e pro- fundidade do solo, do manejo cultural, da direção, espaçamento e largura das fileiras e da altura da latada (Doorenbos \& Kassan, 1994). Allen et al. (1998) citam valores de coeficientes de cultura (Kc) inicial, médio e final da uva iguais a 0,30; 0,85 e 0,45, respectivamente.

Teixeira et al. (1999) determinaram a evapotranspiração de referência (ETo), a evapotranspiração da cultura (ETc) e Kc da uva, em todas as fases do ciclo produtivo, no período de 03/06 a 11/09/1994, em Petrolina, PE. A ETc acumulada foi $503 \mathrm{~mm}$, com valor médio de $4,2 \mathrm{~mm} \mathrm{~d}^{-1}$ e variação diária de 2,8 a 7,0 mm. Os valores de Kc variaram de 0,65 a 1,15 .

De acordo com Ávila Netto (2000), o consumo de água da videira, cultivar Itália, irrigada por gotejamento no Submédio São Francisco, determinado pelo método do balanço de água no solo, no período de 13/05 a 11/08/96 (da poda à colheita dos frutos), foi 333,6 $\mathrm{mm}$. O consumo médio diário foi 3,6 mm sendo que no subperíodo de maior demanda transpiratória da vegetação este valor foi $4,33 \mathrm{~mm}$. Os valores do Kc oscilaram de 0,49 a 0,74.

Os estudos da quantificação das necessidades hídricas das culturas, embora pontuais, podem ser estendidos para regiões mais amplas e, dessa forma, serem disponibilizados parâmetros e dados aos profissionais da área, que têm carência de informações regionais.

Com este trabalho objetivou-se estimar e espacializar a demanda hídrica da cultura da uva na bacia do Rio São Francisco, para servir de subsídio na quantificação do consumo de água pela cultura e no planejamento de projetos hidroagrícolas.

\section{MATERIAL E MÉTODOS}

Foram utilizadas séries históricas de dados diários do clima de 81 localidades selecionadas ao longo de toda a bacia do Rio São Francisco, sendo 28 em Minas Gerais, 38 na Bahia, uma em Sergipe, seis em Alagoas e oito em Pernambuco. Estimaram-se em cada localidade, os valores diários da evapotranspiração de referência (ETo), da precipitação efetiva, da evapotranspiração da cultura (ETc), da demanda suplementar da cultura e da demanda suplementar de irrigação.

A metodologia para determinação da evapotranspiração de referência (ETo), atualmente aceita pelos pesquisadores, é a evapotranspiração de uma cultura hipotética, com uma altura de $0,12 \mathrm{~m}$, resistência aerodinâmica da superfície de $70 \mathrm{sm}^{-1}$ e albedo de 0,23, denominada Método de PenmanMonteith (Sediyama, 1996). Na estimativa da ETo, utilizouse, portanto, o Método de Penman-Monteith. A precipitação efetiva foi determinada com $25 \%$ de probabilidade.

Tanto a ETo quanto a precipitação efetiva, para cada dia do ano, foram obtidas através do software IRRIGA (SISDA 3.5), desenvolvido no âmbito da Universidade Federal de Viçosa (UFV), voltado, entre outras coisas, para o manejo do sistema de irrigação e da água. Neste software utilizaram-se dados das Normais Climatológicas dos anos de 1961 a 1990. 
A evapotranspiração da cultura (ETc), para cada dia do ano, foi calculada utilizando-se a Eq. 1. Utilizou-se, na Eq. 1, Ks igual a 1, por se tratar de irrigação localizada, e $\mathrm{Kl}$ igual a 1, porque a planta cobre a superfície do solo. Os valores de Kc utilizados (Tabela 1) foram os sugeridos por Soares \& Costa (2000), por apresentarem maiores detalhes do Kc nas fases fenológicas da uva e pela coerência com valores encontrados por outros autores na bacia do Rio São Francisco.

$$
\mathrm{ETc}_{\mathrm{i}}=\mathrm{ETo}_{\mathrm{i}} \mathrm{Kc}_{\mathrm{i}} \mathrm{Ks}_{\mathrm{i}} \mathrm{Kl}
$$

em que:

$\mathrm{ETc}_{\mathrm{i}}$ - evapotranspiração da cultura no dia i, mm $\mathrm{ETo}_{\mathrm{i}}$ - evapotranspiração de referência no dia i, mm $\mathrm{Kc}_{\mathrm{i}}$ - coeficiente de cultura no dia $\mathrm{i}$, adimensional

$\mathrm{Ks}_{\mathrm{i}}$ - coeficiente de umidade do solo no dia i, adimensional

Kl - coeficiente de localização, adimensional

A demanda suplementar da cultura, considerando-se a contribuição da chuva, foi obtida utilizando-se as Eqs. 2 e 3.

$$
\begin{aligned}
& \text { DSC }_{\mathrm{i}}=\text { ETc }_{\mathrm{i}}-\text { PrecEfet }_{\mathrm{i}}, \quad \text { se ETc }_{\mathrm{i}}>\text { PrecEfet }_{\mathrm{i}} \\
& \text { DSC }_{\mathrm{i}}=0, \quad \text { se ETc }_{\mathrm{i}}<\text { PrecEfet }_{\mathrm{i}}
\end{aligned}
$$

em que:

$\mathrm{DSC}_{\mathrm{i}}$ - demanda suplementar da cultura no dia i, mm PrecEfet $_{i}$ - precipitação efetiva no dia i, mm

A demanda suplementar de irrigação garante que todas as plantas receberão uma lâmina maior ou igual à necessária, para suprir o déficit hídrico, sendo calculada utilizando-se a Eq. 4. Utilizou-se na Eq. 4 eficiência igual a 70\%, uma vez que avaliações de sistemas de irrigação da cultura da uva feitas na bacia do Rio São Francisco mostraram que, em média, a eficiência dos sistemas de irrigação por microaspersão na cultura da uva é 70\% (Ramos \& Pruski, 2003).

$$
\mathrm{DSI}_{\mathrm{i}}=\frac{\mathrm{DSC}_{\mathrm{i}}}{\mathrm{Ea}} 100
$$

em que:

$\mathrm{DSI}_{\mathrm{i}}$ - demanda suplementar de irrigação no dia i, mm

Ea - eficiência do sistema de irrigação, \%

A partir dos 365 valores diários de cada uma das 81 localidades, obtiveram-se os valores, máximo diário e total anual, da ETo, da ETc, da demanda suplementar da cultura e da demanda suplementar de irrigação.

As simulações foram feitas para a cultivar Itália tipo exportação, iniciando-se na data da primeira poda de produção, e feitas duas podas por ano. Na Tabela 2 são apresentadas as datas de poda, de colheita e os períodos de repouso adotados na simulação.

Tabela 2. Épocas de poda, colheita e repouso da cultura da uva Itália, considerados no modelo de simulação

\begin{tabular}{lcc}
\hline \multicolumn{1}{c}{ Fases } & Datas & Duração (dias) \\
1a Poda & $01 / 01$ & 130 \\
$1^{\text {a } \text { Colheita }}$ & $10 / 05$ & \\
Período de repouso & $11 / 05$ a $30 / 06$ & 51 \\
& $01 / 07$ & 130 \\
$2^{\text {a Poda }}$ & $07 / 11$ & \\
$2^{\text {a } \text { Colheita }}$ & $08 / 11$ a $31 / 12$ & 54 \\
Período de repouso & & \\
\hline
\end{tabular}

Os mapas temáticos da distribuição espacial dos valores máximo diário e total anual, da evapotranspiração da cultura, da demanda suplementar da cultura e da demanda suplementar de irrigação foram obtidos com o uso do ArcView, versão 3.2a, empregando-se o interpolador IDW.

\section{RESULTADOS E DISCUSSÃO}

Os mapas temáticos da distribuição espacial dos valores da ETo máxima diária e da ETo total anual são apresentados nas Figuras $1 \mathrm{~A}$ e $1 \mathrm{~B}$, respectivamente.

Verifica-se que os valores máximos diários (Figura 1A)

\begin{tabular}{|c|c|c|}
\hline Fases fenológicas & $\begin{array}{l}\text { Duração } \\
\text { (dias) }\end{array}$ & Kc \\
\hline Repouso que antecede a poda & 30 & $\begin{array}{l}\text { Durante esta fase, deve-se reduzir a lâmina de água aplicada a um valor mínimo (Kc entre } 0,15 \text { e } 0,25 \text { ), } \\
\text { visando manter a planta verde, não permitindo, porém, a emissão de brotos novos. Durante os } 10 \text { dias que } \\
\text { antecedem a poda, elevar as lâminas de irrigação com base em valores de Kc entre } 0,7 \text { e } 0,9 \text {, para recompor } \\
\text { plenamente o nível ideal de umidade do solo. Este procedimento ajudará também a aumentar, ao máximo, } \\
0 \text { fluxo de seiva na planta logo após a poda e, conseqüentemente, auxiliar na brotação das gemas. }\end{array}$ \\
\hline Brotação e crescimento dos ramos & 30 & $\begin{array}{l}\text { Logo após a poda, as lâminas de água devem ser calculadas com valores de } \mathrm{Kc} \text { entre } 0,4 \text { e } 0,5 \text {, mas } \\
\text { devem também ser elevadas progressivamente com o crescimento dos ramos, devendo alcançar } 0 \text { valor de } \\
0,6 \text { aos } 25 \text { dias após a poda. }\end{array}$ \\
\hline Floração até chumbinho & 10 & $\begin{array}{l}\text { Devem-se evitar irrigações excessivas, mantendo-se o valor de Kc igual a 0, } 6 \text { para não causar abortamento } \\
\text { de flores. }\end{array}$ \\
\hline $1^{\text {a }}$ fase de crescimento das bagas & 30 & Fase em que a demanda de água é máxima, com valores de Kc entre 0,8 e 0,9 . \\
\hline Fase de parada de crescimento das bagas & 20 & Nesta fase, a dotação de água deve ser reduzida para valores de Kc entre 0,5 e 0, 6. \\
\hline $2^{a}$ fase de crescimento das bagas & 25 & $\begin{array}{l}\text { Nesta fase, o consumo da videira volta novamente a ser máximo, em decorrência do reinício do crescimento } \\
\text { das bagas, e o Kc adotado deve situar-se entre } 0,8 \text { e } 0,9 \text {. }\end{array}$ \\
\hline Maturação até a colheita & 15 & Os valores de Kc variam de 0,4 a 0,6 \\
\hline
\end{tabular}
e total anual (Figura 1B) da ETo aumentam à medida que se avança da porção sul para a norte da bacia, chegando a

Tabela 1. Valores de Kc da cultura da uva 
A.

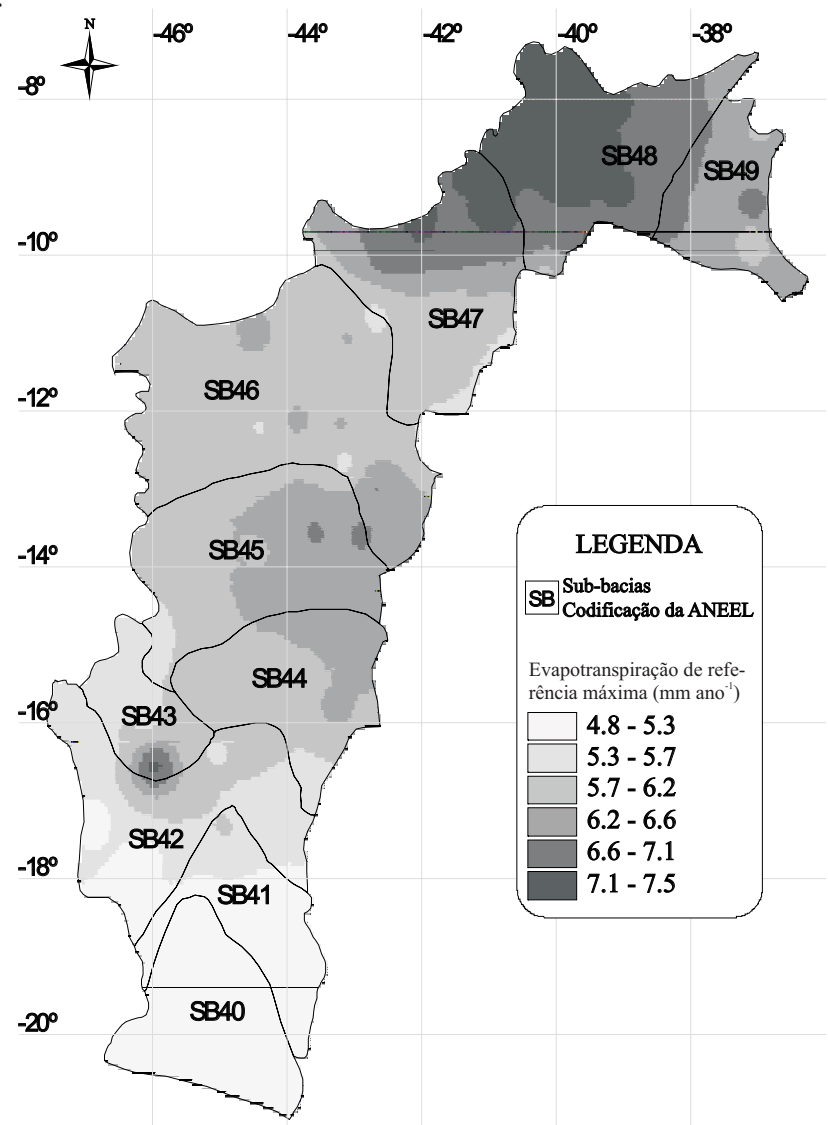

B.

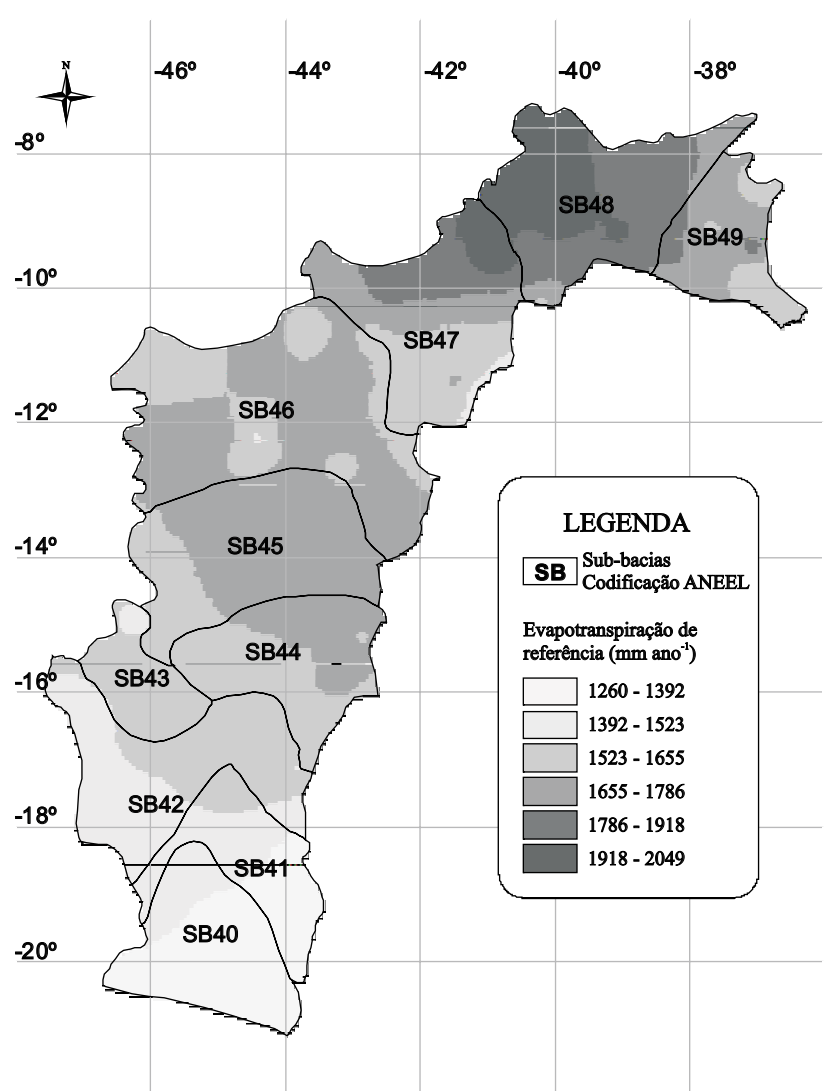

Figura 1. Valores máximo diário (A) e total anual (B) da evapotranspiração de referência na bacia do Rio São Francisco apresentar valor máximo de 7,51 $\mathrm{mm} \mathrm{d}^{-1}$ em Santa Cruz, PE e Sobradinho, BA, ambas na sub-bacia 48. Tais mapas servem como parâmetro para o gerenciamento do uso da água, por exemplo, em locais com maior taxa de evapotranspiração anual deverá se optar pela implantação de culturas irrigadas por sistemas de aplicação localizada, a fim de evitar perdas por evaporação direta.

Os mapas temáticos da distribuição espacial dos valores da ETc máxima diária e da ETc total anual são apresentados nas Figuras 2A e 2B, respectivamente.

O mapa de valores máximos diários (Figura 2A) da ETc pode ser usado como base para dimensionamento de projetos de irrigação da cultura da uva, visando atender às necessidades hídricas da cultura em épocas mais críticas ao longo do ano, possibilitando trabalhar com maior margem de segurança, em casos de veranicos. No entanto, a não-contabilização das eventuais precipitações poderá implicar no superdimensionamento de projetos, acarretando maiores custos. A partir de seus valores espacializados, podem-se estimar, para fins de projeto, os períodos de irrigação, o turno de rega e a rede hidráulica para determinada região, dentro da bacia, cultivada com uva.

Verificou-se que os valores máximo diário (Figura 2A) e total anual (Figura 2B) da ETc aumentaram na medida em que se avançou do sul para o norte da bacia, porém, em grande parte da bacia, se observou o predomínio de valores da ETc máxima diária variando na faixa de 4,5 a 5,7 mm d-1.

Com relação à Figura 2B, tem-se que os maiores valores da ETc anual foram da ordem de 1025 a 1173 mm, abrangendo parte da SB47 e praticamente toda a SB48 (região em que se concentra grande parte da produção de uva da bacia). A ETc média anual para toda a bacia foi $943 \mathrm{~mm}$.

Os mapas temáticos da distribuição espacial dos valores máximo diário e total anual da demanda suplementar da cultura estão apresentados nas Figuras 3A e 3B, respectivamente.

Os valores máximos diários da demanda suplementar da cultura foram praticamente iguais aos da ETc. As pequenas reduções observadas foram mais evidenciadas na porção sul da bacia, onde o regime pluvial se concentra entre os meses de outubro e março, período em que se observam os maiores valores da ETc. Sempre que se avança para a porção norte da bacia, a estação chuvosa tende a atrasar para os meses subseqüentes, resultando em menores reduções; além disso, os baixos valores totais de chuva observados na porção norte, comparados com os da porção sul, contribuem para a ocorrência de menores diferenças entre a demanda suplementar e a ETc.

Em média, a demanda suplementar da cultura na bacia foi $839,5 \mathrm{~mm}^{\mathrm{ano}}{ }^{-1}$, 103,5 mm inferior à ETc, sendo esta redução mais evidenciada na porção sul da bacia. Na cidade de Pirapora, MG a demanda de irrigação passou de 934 para $835 \mathrm{~mm} \mathrm{ano}^{-1}$, devido à contribuição da precipitação efetiva. Na região da divisa entre as sub bacias 47 e 48 (região de Sobradinho, BA e do pólo Juazeiro/Petrolina), onde se concentra grande parte da produção de uva na bacia, a redução da demanda de irrigação pela contribuição da precipitação pode ser considerada insignificante. 
A.

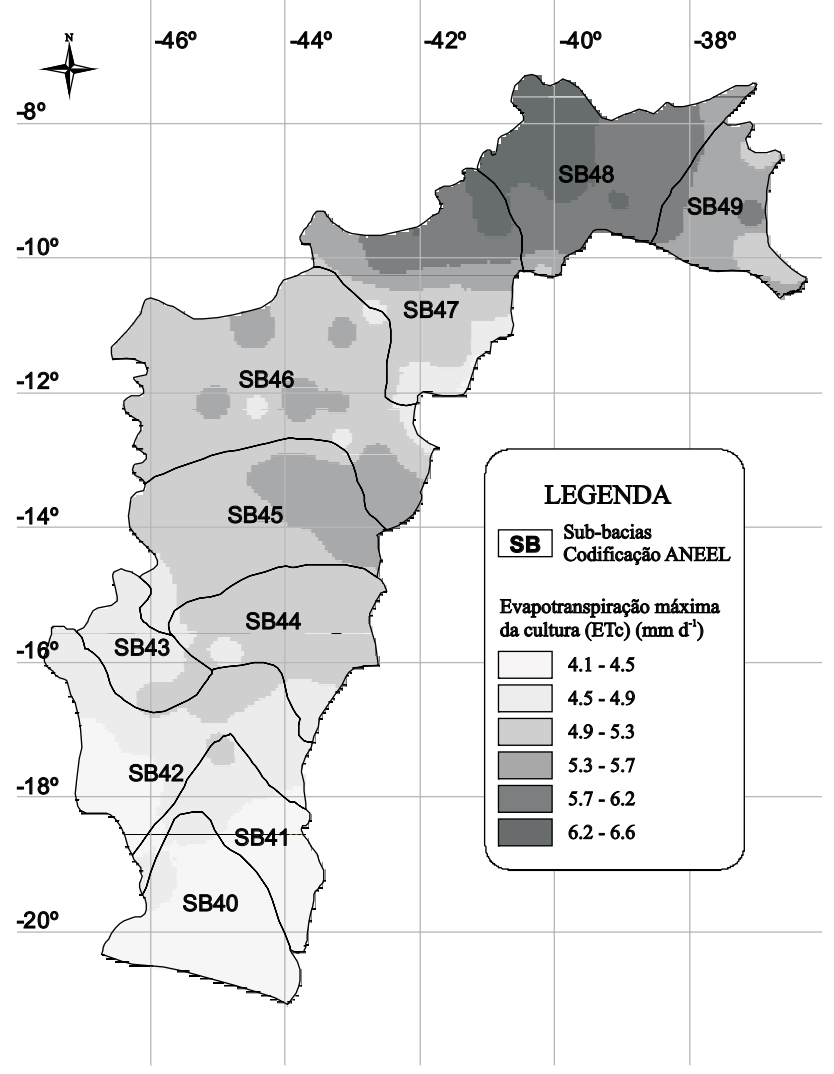

B.

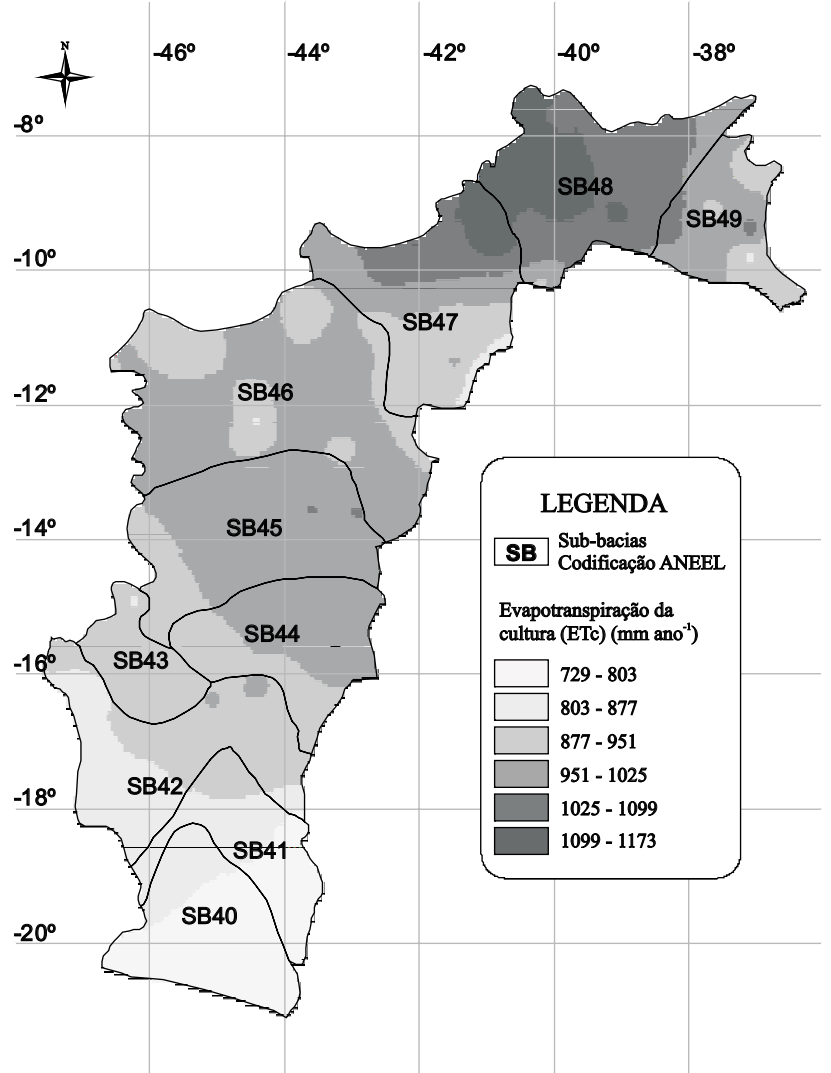

Figura 2. Valores máximo diário (A) e total anual (B) da evapotranspiração da cultura da uva na bacia do Rio São Francisco
A.

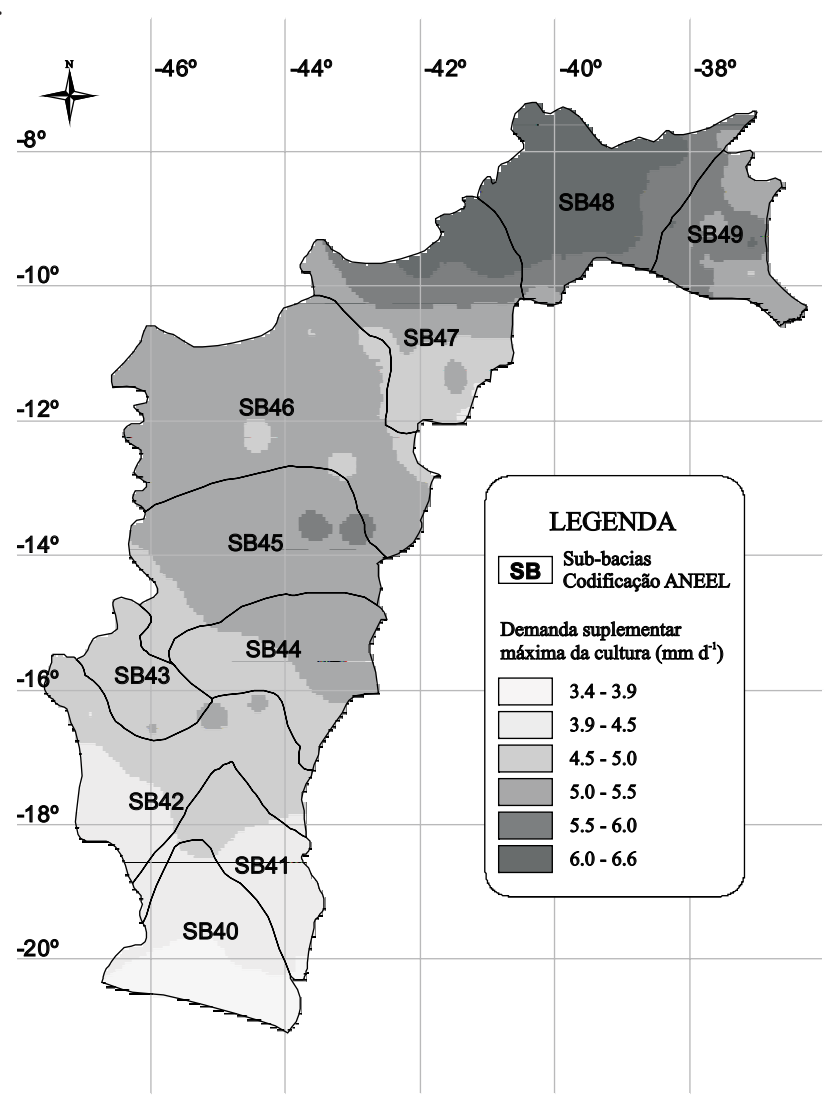

B.

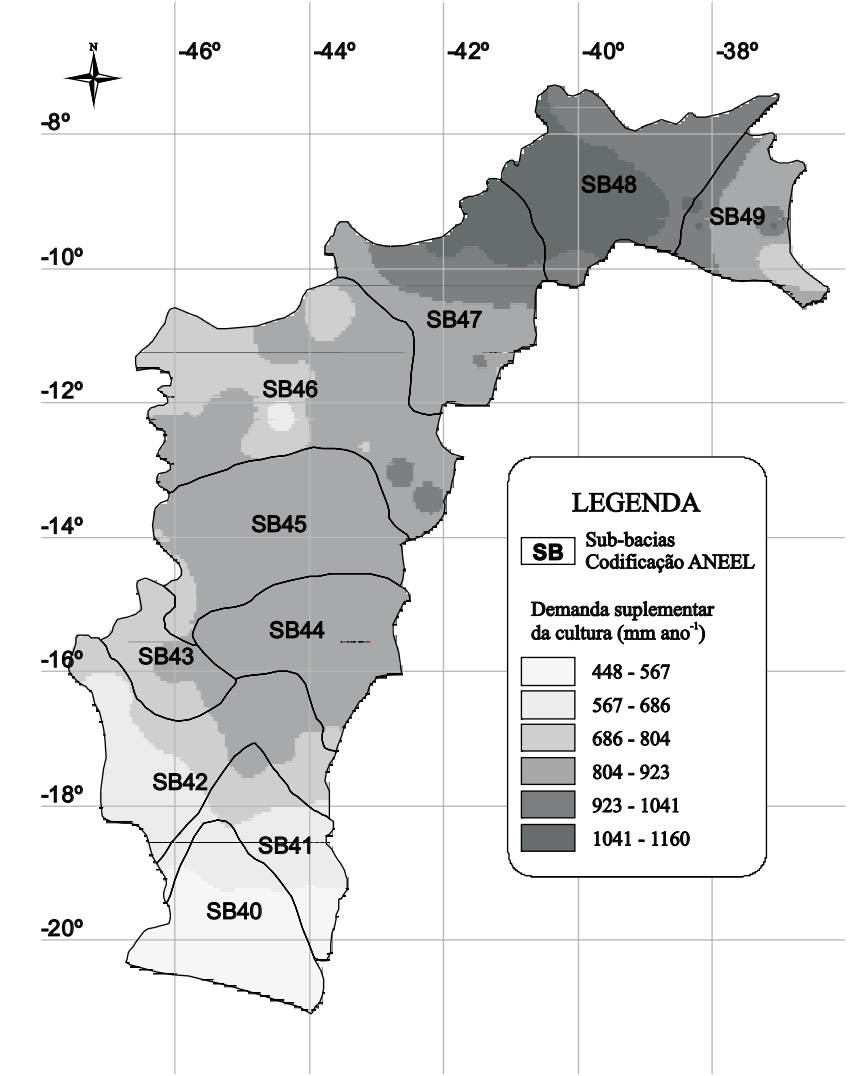

Figura 3. Valores máximo diário (A) e total anual (B) da demanda suplementar da cultura da uva na bacia do Rio São Francisco

R. Bras. Eng. Agríc. Ambiental, v.10, n.3, p.563-569, 2006. 
A.

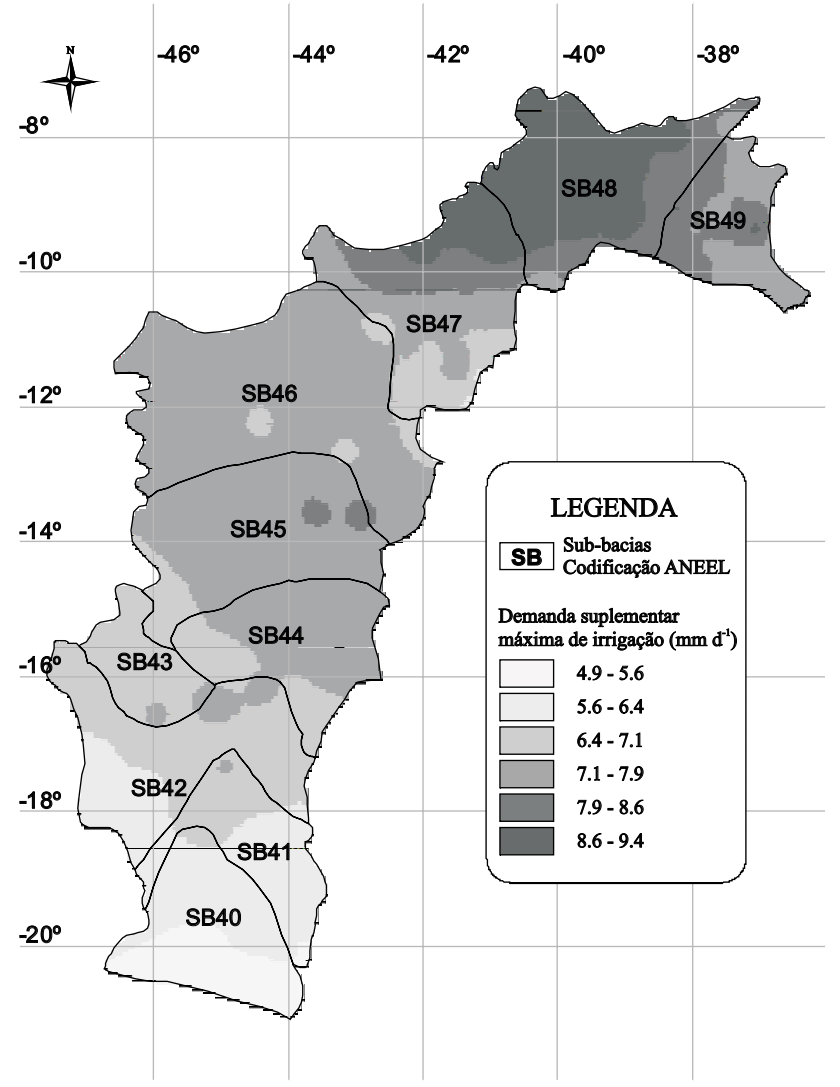

B.

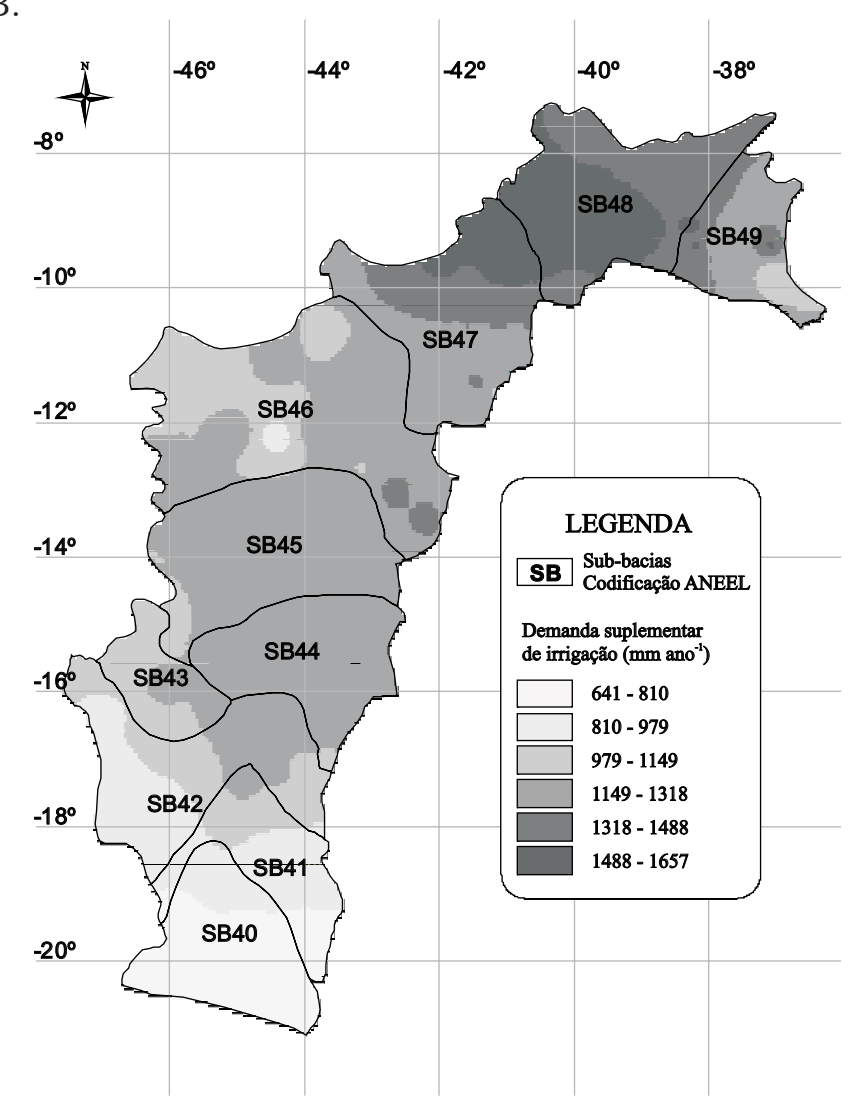

Figura 4. Valores máximo diário (A) e total anual (B) da demanda suplementar de irrigação para a cultura da uva, com sistema de irrigação com eficiência de $70 \%$, na bacia do Rio São Francisco
Os mapas temáticos da distribuição espacial dos valores máximo diário e total anual da demanda suplementar de irrigação (sistema de irrigação com eficiência de 70\%) são apresentados nas Figuras 4A e 4B, respectivamente.

A demanda suplementar de irrigação máxima diária (Figura 4A) teve valor médio de 7,4 mm e valor máximo de 9,7 mm em Santa Cruz, PE (SB 48).

Para efeito de comparação, pode-se verificar, por exemplo, que a demanda suplementar máxima da cultura na cidade de Pirapora, MG e no pólo Juazeiro/Petrolina, que era 5,0 e $6,2 \mathrm{~mm} \mathrm{~d}^{-1}$, passou a 7,2 e $8,8 \mathrm{~mm} \mathrm{~d}^{-1}$, respectivamente, ao se considerar a eficiência do sistema. Esse aumento é significativo, pois implica em menor intervalo entre irrigações, ampliação da rede hidráulica, maior gasto de energia, onerando os custos operacionais, e maior consumo de água, que é cobrada nos perímetros irrigados.

A demanda suplementar de irrigação (Figura 4B) foi, em média na bacia, $1.199 \mathrm{~mm}^{2} \mathrm{ano}^{-1}$, com valor máximo de $1.659 \mathrm{~mm}^{2} \mathrm{ano}^{-1}$ em Sobradinho, BA. Tal demanda em Pirapora, MG e no pólo Juazeiro/Petrolina foi 1.193 e $1.553 \mathrm{~mm}$ ano $^{-1}$, respectivamente.

Para evidenciar a necessidade de aumentar a eficiência dos sistemas de irrigação na bacia, considerou-se a demanda suplementar da cultura da uva nas microrregiões de Petrolina, BA e Juazeiro, PE igual a 1.041,5 mm ano-1 (média entre os intervalos predominantes nas microrregiões, 923 e $1.160 \mathrm{~mm} \mathrm{ano}^{-1}$ ). Sendo 5.691 ha a área total cultivada com uva nessas duas microrregiões, haveria uma demanda anual de $59.271 .765 \mathrm{~m}^{3}$ de água para suprir as deficiências hídricas da cultura da uva. Considerando-se a eficiência de 70\%, a demanda suplementar de irrigação seria 1.487,5 mm anuais (média dos intervalos 1.318 e $1.657 \mathrm{~mm} \mathrm{ano}^{-1}$ ), o que implicaria em um consumo anual de $84.653 .625 \mathrm{~m}^{3}$, ou seja, um acréscimo de $25.381 .860 \mathrm{~m}^{3}$ de água por ano, em relação ao sistema funcionando com $100 \%$ de eficiência.

Caso os sistemas e/ou os manejos fossem melhorados e passassem a operar com 90\% de eficiência, valor recomendado para sistemas de irrigação por microaspersão, a demanda suplementar de irrigação nas microrregiões de Juazeiro e Petrolina seria aproximadamente $1.157 \mathrm{~mm}^{2} \mathrm{ano}^{-1}$ e consumo anual de $65.844 .870 \mathrm{~m}^{3}$ de água, propiciando uma economia 18.808.755 $\mathrm{m}^{3}$, em relação ao sistema funcionando com $70 \%$. Isso permitiria agregar mais 1.626 ha de uva, sem aumentar a demanda de água para irrigação.

\section{CONCLUSÕES}

1. A evapotranspiração máxima diária da cultura da uva (ETc) variou, em grande parte da bacia, entre 4,5 e 5,7 mm, sendo o valor médio anual de $943 \mathrm{~mm}$.

2. A demanda suplementar da cultura foi, em média, $839,5 \mathrm{~mm}$, enquanto a demanda suplementar de irrigação (sistema funcionando com $70 \%$ de eficiência) foi $1.199 \mathrm{~mm}$.

3. Somente para as microrregiões de Juazeiro, BA e Petrolina, PE, se fossem adotadas melhores estratégias de manejo e o sistema passasse a operar com eficiência de $90 \%$, 
em vez de 70\%, haveria uma economia de água de, aproximadamente, $18.808 .755 \mathrm{~m}^{3}$, o que permitiria agregar mais 1.626 ha de videiras, sem aumentar a demanda de água para irrigação.

\section{LITERATURA CITADA}

Allen, R. G.; Pereira, L. S., Paes, D.; Smith, M. Crop evapotranspiration: guidelines for computing crop water requirements. Roma: FAO, 1998, 328p, .Irrigation and Drainage Paper, 56

Ávila Netto, J.; Azevedo, P. V. de; Silva, B. B.; Soares, J. M.; Teixeira, A. H. de C. Exigências hídricas da videira na região do Submédio São Francisco. Pesquisa Agropecuária Brasileira, Brasília, v.35, n.8, p.1559-1556, 2000.

Carvalho, D. F. de. Otimização do uso da água no perímetro irrigado do Gorutuba. Viçosa: UFV, 1998. 145p. Tese Doutorado

Dantas Neto, F. S. Recursos hídricos e suporte tecnológico a projetos hidroagrícolas: Bacia do Alto São Francisco , (ed.) Euclydes, H. P.; Ferreira P. A.; Viçosa: UFV; Belo Horizonte: RURALMINAS; Brasília: ANA, 2002. 258p.

Doorenbos, J.; Kassam, A. H. Efeito da água no rendimento das culturas. Campina Grande: UFPB, 1994. 306p. Estudos FAO: Irrigação e Drenagem, 33.
IBGE - Instituto Brasileiro de Geografia e Estatística. Produção Agrícola Municipal. Rio de Janeiro, 2002. http//www.ibge.gov.br/ Produção_Agrícola/ Produção_Agrícola_Municipal_\%Banual\%05D/ 2002/micro_meso_municipios. 31 Jul. 2004, 2002.

Protas, J. F. S.; Camargo, H. A.; Melo, L. M. R. A vitivinicultura brasileira: Realidade e perspectivas. <http://www.cnpuv.embrapa.br/ vitivini.html>. Acesso em: 25 de julho 2004.

Ramos, M. M.; Pruski, F. F. Quantificação e análise da eficiência do uso da água pelo setor agrícola na Bacia do São Francisco. In: Relatório do Projeto de gerenciamento integrado das atividades desenvolvidas em terra na Bacia do São Francisco, 2003. $<$ http://www.ana.gov.br/gefsf/arquivos/ ResumoExecutivo43.pdf.>.18 de Dez. 2003.

Sediyama, G. C. Necessidade de água para os cultivos.In: Curso de Engenharia de Irrigação-módulo 2, Brasília : ABEAS, 1996. 143p..

Soares, J. M.; Costa, F. F. Irrigação da cultura da videira. A viticultura no semi-árido brasileiro. In: Leão, P. C. de S., Soares J. M. (ed.) Petrolina: Embrapa Semi-árido, 2000. 366p.

Teixeira, A. H. C.; Azevedo, P. V. Zoneamento agroclimático para a videira européia no Estado de Pernambuco, Brasil. Revista Brasileira de Agrometeorologia, Santa Maria, v.4, n.1, p.137-141, 1996.

Teixeira, A. H. C.; Azevedo, P. V.; Silva, B. B.; Soares, J. M. Consumo hídrico e coeficiente de cultura da videira na região de Petrolina, PE. Revista Brasileira de Engenharia Agrícola e Ambiental, Campina Grande, v.3, n.3, p.413-416, 1999. 